\title{
ERGONOMICS IN CONSTRUCTION: WHERE DOES IT HURT?
}

\author{
John Smallwood, \\ Department of Construction Management, \\ University of Port Elizabeth, South Africa \\ Claire Wheeler, \\ OCCUMED cc, \\ Cape Town, South Africa \\ Danie Venter, \\ Institute for Statistical Consultation and Methodology, \\ University of Port Elizabeth, South Africa
}

\begin{abstract}
Construction requires, inter alia, bending and twisting, working in awkward or cramped positions, reaching away from the body and overhead, repetitive movements, handling heavy materials and equipment, use of body force, exposure to vibration and noise, and climbing and descending.

Interviews conducted with workers using a structured questionnaire and a graphic inquiry determined, inter alia: the hands, feet and lower back are mostly used; the lower and upper back hurt most, and climbing and descending, and handling heavy materials predominate among ergonomic problems encountered.

Keywords: construction, ergonomics, workers, hurt
\end{abstract}

\section{LITERATURE SURVEY}

\section{Introduction}

The Center to Protect Workers' Rights (CPWR) (1997) cites statistics provided by the US Bureau of Labor Statistics. The rate of sprains and strains in construction -1.8 per 100 full-time equivalent workers - is the second highest of all industries. Sprains and strains $(37 \%)$ predominated in terms of the nature of injuries and illness resulting in days away from work. The rate of back injuries in construction -1.2 per 100 full-time equivalent workers - is the second highest of all industries. The back predominated in terms of anatomic region affected by non-fatal injuries.

\section{'Problem' occupations}

According to Hsiao \& Fosbroke (1997) an analysis of injury data indicates that eleven occupations are "at increased risk" as they represent $31 \%$ of the workforce, but account for $62 \%$ of the overexertion injuries. The occupations are general workers, carpenters, plumbers, drywall installers, roofers, electricians, structural metal workers, carpet layers, tile setters, plasterers and machine operators.

\section{Ergonomic problems}

Based upon a score out of 10 , research conducted among six trades in the USA determined the following to be the top five ergonomic problems: working in the same position for long periods (5.67); bending or twisting the back in an awkward way (5.46); working in awkward or cramped positions (5.00); working when injured or hurt (4.69), and handling heavy materials or equipment (4.63) (Zimmerman et al., 1997).

\section{Where does it hurt?}

Research conducted among electricians in the USA determined the following anatomic regions to be the top five in terms of the frequency they were reported to be a problem: lower back (66.6\%); knee (45.9\%); wrist/hand (43.6\%); neck (37.2\%), and shoulder (37.1\%) (Cook et al., 1997). Other research conducted among six trades in the USA determined the lower back to predominate in terms of the anatomic regions where workers experienced a problem, followed by the knee, wrist/hand, shoulder and neck (Zimmerman et al., 1997). 


\section{RESEARCH}

Four general contractors (GCs) facilitated the interviewing of 84 construction workers using a structured interview. A total of 71 usable questionnaires were analyzed. Thirteen respondents either did not comply with the 'production' worker requirement, or were incomplete. Of the 71 respondents included in the analysis, $46.5 \%$ were general workers, $12.7 \%$ semi-skilled, $12.7 \%$ artisans (craft workers), $9.9 \%$ operators and $8.5 \%$ apprentices. The mean age was 36.9 and the median 34 years, the youngest worker being 19 years and the oldest being 62 years of age. On average the workers had worked 14.1 years in construction and 8.6 years for their current employer, the median being 11.1 and 5.8 years respectively.

Concreting $(57.7 \%)$ predominated in terms of the work workers mainly did or were involved with, followed by formwork (45.1\%), excavating (39.4\%), and carpentry $(22.5 \%)$

Table 1 presents the top nine of a total of eighteen ergonomic problems based on the daily, weekly, fortnightly, monthly or non-exposure thereto. Given the possible range of responses in terms of frequency, an importance index (II), with a maximum of four and a minimum of zero, was computed to enable ranking of the problems. With the exception of 'climbing \& descending', most of the top nine ranked problems are cited in international literature, inter alia, Zimmerman et al. (1997) and Cook et al. (1997). Climbing and descending has previously been determined to be a problem in South Africa (Smallwood, 1997).

Given the range of the II, it is notable that all the values in Table 2 are above the midpoint of 2.00, implying that all nine problems can be regarded as prevalent.

Only $22.9 \%$ of respondents indicated that reference was 'always' made to the correct use of tools/body and position when instruction to execute a task is given. $58.6 \%$ responded in the negative.

Table 2 indicates that the majority of workers identified the various aspects which 'require attention'.

Workers were requested to graphically indicate the anatomic regions they mostly use at work, where they have pain and to state when the pain occurs.
Table 1

Top nine ranked 'ergonomic' problems

\begin{tabular}{lcc}
\hline Problem & Ranking & I I \\
\hline Climbing \& descending & 1 & 3.23 \\
Handling heavy materials & 2 & 3.00 \\
Repetitive movements & 3 & 2.97 \\
Handling heavy equipment & 4 & 2.87 \\
Use of body force & 5 & 2.77 \\
Exposure to noise & 6 & 2.65 \\
Bending or twisting the back & 7 & 2.38 \\
Staying in the same position & 8 & 2.30 \\
Working in awkward positions & 9 & 2.30 \\
\hline
\end{tabular}

Table 2

'Ergonomic' aspects which require attention

\begin{tabular}{lc}
\hline Aspect & Yes response (\%) \\
\hline Materials handling & 92.6 \\
Materials storage & 90.4 \\
Working platforms & 88.5 \\
Means of ascending/descending & 84.6 \\
Housekeeping & 84.6 \\
Walkways & 82.7 \\
Mechanization & 73.1 \\
Circulation roads & 67.3 \\
Circulation paths & 65.4 \\
\hline
\end{tabular}

Table 3 presents the top nine of a total of eighteen anatomic regions in terms of use, the percentage respondents who experienced pain when using a particular anatomic region, and the percentage respondents who experienced pain in a particular anatomic region irrespective of its use. Hands 
(93\%) predominated in terms of the anatomic regions mostly used, followed by the feet $(78.9 \%)$ and lower back $(66.2 \%)$. Knees $(52.1 \%)$ and shoulders $(40.8 \%)$ were used relatively frequently. The upper back $(78.6 \%)$ and the lower back $(66 \%)$ predominated in terms of percentage of the anatomic regions which hurt of those mostly used. The lower back $(43.7 \%)$ predominated in terms of the anatomic regions which pain, irrespective of use.

Table 3

Anatomic regions used and frequency of pain

\begin{tabular}{lccc}
\hline Part & Use $(\%)$ & Pains/Use & Pains \\
& & $(\%)$ & irrespective $(\%)$ \\
\hline Hands & 93.0 & 9.1 & 8.5 \\
Feet & 78.9 & 8.9 & 7.0 \\
Lower back & 66.2 & 66.0 & 43.7 \\
Knees & 52.1 & 13.5 & 7.0 \\
Shoulders & 40.8 & 34.5 & 14.1 \\
Lower legs & 31.0 & 22.7 & 7.0 \\
Neck & 26.8 & 31.6 & 8.5 \\
Elbows & 25.4 & 5.6 & 1.4 \\
Upper back & 19.7 & 78.6 & 15.5 \\
\hline
\end{tabular}

\section{CONCLUSIONS}

Sprains and strains predominate in terms of the nature of injuries.

The hands, feet and lower back predominate in terms of the anatomic regions mostly used, and the lower back in terms of the anatomic region which hurts most frequently.

The 'ergonomic' problems stem from the nature of the construction process, inter alia, heavy materials and equipment, unit materials, minimal pre-fabrication and preassembly, constricted work areas and insufficient mechanization.

\section{RECOMMENDATIONS}

Constructability reviews conducted during the design process should address ergonomics.

Design and details should be simple and should complement the use of system formwork, pre-fabrication, preassembly and mechanization do reduce the effects of various ergonomic problems.

\section{REFERENCES}

Cook, T.M., Zimmerman, C.L., \& Rosecrance, J.C. (1997). Self-reported musculoskeletal symptoms and job factors among unionized electricians. In proceedings of the $13^{\text {th }}$ Triennial Congress of the IEA, Tampere, Finland, 6. P. Seppäla, T. Luopajärvi, C-H. Nygård, \& M. Mattila (Eds), From Experience to Innovation. (pp.160-162). Helsinki: Finnish Institute of Occupational Health.

Hsiao, H., \& Fosbroke, D. (1997). Determining research focus for reducing overexertion injuries in the construction industry. In proceedings of the $13^{\text {th }}$ Triennial Congress of the IEA, Tampere, Finland, 6. P. Seppäla, T. Luopajärvi, C-H. Nygård, \& M. Mattila (Eds), From Experience to Innovation. (pp.118-120). Helsinki: Finnish Institute of Occupational Health.

Smallwood, J.J. (1997). Ergonomics in construction. In proceedings of the $13^{\text {th }}$ Triennial Congress of the IEA, Tampere, Finland, 6. P. Seppäla, T. Luopajärvi, C-H. Nygård, M. Mattila (Eds), From Experience to Innovation. (pp.184-187). Helsinki: Finnish Institute of Occupational Health.

Zimmerman, C.L., Cook, T.M. \& Rosecrance, J.C. (1997). Trade specific trends in self-reported musculoskeletal symptoms and job factor perceptions among unionized construction workers. In proceedings of the $13^{\text {th }}$ Triennial Congress of the IEA, Tampere, Finland, 6. P. Seppäla, T. Luopajärvi, C-H. Nygård, \& M. Mattila (Eds), From Experience to Innovation. (pp.214-216). Helsinki: Finnish Institute of Occupational Health. 